\title{
Impact of a medical student alcohol intervention workshop using recovering alcoholics as simulated patients
}

This article was published in the following Dove Press journal:

Advances in Medical Education and Practice

7 May 2014

Number of times this article has been viewed

\section{J Aaron Johnson' \\ J Paul Seale'}

Sylvia Shellenberger ${ }^{1}$

Mary MVelasquez ${ }^{2}$

Candice Alick'

Katherine Turk ${ }^{3}$

'Department of Family Medicine, Medical Center of Central Georgia and Mercer University School of Medicine, Macon, GA, ${ }^{2}$ School of Social Work, University of TexasAustin, Austin, TX, ${ }^{3}$ Department of Surgery, University of AlabamaBirmingham, Birmingham, AL, USA

Correspondence: J Aaron Johnson Department of Family Medicine, Medical Center of Central Georgia and Mercer University School of Medicine, 3780 Eisenhower Parkway, Suite 3, Macon, GA 31206, USA

Tel +l 4786335548

Fax + I 4786335575

Email johnson.aaron@mccg.org
Background: Alcohol screening and brief intervention (SBI) reduces drinking among at-risk drinkers. Lack of training and negative attitudes represents a barrier to SBI performance. This study evaluates the impact of a medical student workshop using recovering alcoholics in simulated patient interviews to teach SBI skills.

Methods: Third-year students ( $\mathrm{n}=94)$ were surveyed before and after a 3-hour alcohol SBI workshop regarding their perceived importance and confidence in performing eleven SBI behaviors. Students were also asked to list factors increasing and decreasing motivation to conduct SBI. Students completing off-campus rotations $(n=71)$ served as controls, completing surveys during the same time period but without attending the workshop.

Results: Analysis of variance found a significant interaction effect between the students participating in the workshop and control students on both importance scores $[F(2,174)=3.34]$ and confidence scores $[F(2,174)=9.13]$, indicating higher scores for the workshop students at the follow-up time periods. Commonly listed motivators for performing SBI included clinical experience with alcohol misuse and the impact of alcohol on health and relationships. High relapse rates and patient reactions to questions about alcohol use decreased the motivation to perform SBI.

Conclusion: SBI workshops that include recovering alcoholics as simulated patients can produce long-term improvements in students' perceived importance and confidence in performing SBI.

Keywords: alcohol, screening, medical students, brief intervention

\section{Introduction}

Despite widespread evidence of the health impact and economic importance of alcohol misuse worldwide ${ }^{1-3}$ and evidence that simple brief interventions by physicians can reduce alcohol misuse and related health care consequences, ${ }^{4-9}$ physician screening and brief intervention (SBI) is infrequently performed, ${ }^{10-14}$ with many physicians reporting inadequate training in this area. ${ }^{15-22}$ For several decades, key national and international organizations including the World Health Organization, American Medical Council on Mental Health, Medical Council on Alcoholism, and Office of National Drug Control Policy have called for increased education about alcohol misuse for students in medical schools. ${ }^{23-28}$

Surveys of medical students have revealed frequent negative attitudes toward patients with drug and alcohol problems, ${ }^{29-32}$ with one study indicating that the attitudes of medical students worsen during medical training. ${ }^{32}$ Because a strong correlation has been identified between physicians' attitudes, confidence, and role legitimacy on 
reported screening and treatment practices with patients who misuse alcohol and other drugs, ${ }^{32,33}$ alcohol training programs typically target clinicians' attitudes, as well as their knowledge and skills. The goal of such training is to dispel any existing biases against these patients and increase clinicians' commitment to addressing patterns of misuse, as well as their medical or surgical consequences. ${ }^{30,34,35}$ Numerous programs designed for practicing clinicians indicate that a combination of didactic education and skills training increases clinicians' confidence in performing alcohol SBI and increases rates of alcohol intervention. ${ }^{34,36-42}$

A 2000 review of the existing literature by El-Guebaly et al concluded that improving medical students' knowledge and skills was easier to obtain than attitudinal shifts. ${ }^{43}$ Two studies from the early 1990s reported changes in student attitudes using a model substance abuse curriculum and an intensive interactive seminar, including seminars, 12-step meeting attendance, and role plays with standardized patients; however, changes were not sustained during clinical training. ${ }^{44,45}$ Two clinical training experiences from the last decade report positive attitudinal change. Silins et al found that a clinical rotation including 2 weeks on an addiction treatment unit resulted in decreased dislike of problem drinkers, a greater sense of responsibility towards providing intervention, and less anticipation of discomfort working with these patients. ${ }^{30}$ Similarly, Christison and Haviland found that 1-week in addiction medicine as part of a psychiatry rotation changed students' perceptions of working with patients with substance abuse problems. Following the rotation, students were more likely to describe the patients as treatable, and worthy of medical resources. ${ }^{35}$

Similarly, workshops have been utilized to teach SBI skills and improve student attitudes toward patients with substance use problems. Two trials of 3-hour interventions in Australia found that both simple didactic training and a combination of didactic plus experiential training improved student attitudes toward patients misusing alcohol, although neither was sufficient to provide students with adequate brief intervention skills. ${ }^{42,46}$ Kahan et al found that a 3-hour skills-based workshop resulted in increases in knowledge of drinking reduction strategies, increases in assessment and management scores, and increases in self-efficacy, although commitment to treatment returned to near-baseline levels at the 4-month follow-up. ${ }^{47}$ Comparison of a brief intervention lecture versus a rich media web module resulted in increases in confidence to perform brief intervention in both groups, with web-trained students achieving higher brief intervention scores on observed structured clinical examinations; however, no information on attitudes or long-term outcomes is available..$^{48}$

Standardized and simulated patient interviews (SPs) are a preferred strategy for teaching skills because they provide a safe learning environment, opportunity for feedback, and increase learners' self-confidence. ${ }^{49,50}$ Use of recovering alcoholics as SPs to teach alcohol interview skills offers unique potential advantages: practice interviews with emotionally authentic SPs in stable recovery might increase student confidence in alcohol brief intervention while also increasing their sense of the importance of engaging patients in conversations about their alcohol misuse. A 2012 literature search found no prior studies that examined the attitudinal impact of utilizing recovering alcoholics as SPs in alcohol intervention workshops.

The following analysis describes a 3-year evaluation of an alcohol training workshop designed to produce long-term increases in students' perceived importance and confidence in performing the specific components of alcohol SBI and to explore factors which increase or decrease students' motivation to perform brief interventions.

\section{Materials and methods}

In this study, approved by the Mercer University institutional review board, third-year medical students participating in their family medicine rotation provided appropriate written consent and then completed a baseline attitudes survey which measured their perceived importance of and confidence in executing eleven behaviors related to alcohol screening, intervention, and referral. The behavior list was developed based on components of effective SBI intervention studies described in the US Preventive Services Task Force's recommendation statement advocating alcohol screening and behavioral counseling for all adult primary care patients. ${ }^{51}$ Students were asked to rate these Likert scale items on a scale of 1 to 10, with 1 representing low importance/confidence and 10 representing high importance/confidence. Evaluation also included two open-ended questions: "List any aspect(s) of your medical training that has (have) increased (or decreased) your motivation to screen and intervene with patients who are problem drinkers."

Of 172 students invited to participate, 165 were consented and completed the baseline survey. Students at the medical school's main campus $(n=94)$ then participated in an alcohol intervention workshop, while students completing their family medicine rotation at off-campus sites $(n=71)$ served as study controls. While students were allowed to select the location of their rotation, with the exception of the alcohol 
intervention workshop, the education experience is similar across sites. All graded components, readings, testing, and student evaluations were identical and coordinated from one campus by a single coordinator. Although not randomized to these locations, there should not be any systematic differences between students electing local rotations and those in other locations.

The skills-based intervention workshop included a 1-hour lecture on the components of alcohol SBI, a 15-minute practice interview with a recovering SP that allowed them to practice the skills covered in the lecture, then a debriefing feedback session for all students and patients. A typical workshop would include five to eight recovering SPs. Over the duration of the study, approximately 35 recovering persons served in SP roles. While some SPs participated in a 2-hour training session which included practice interviews, most participated only in a half-hour orientation using a twopage description of the role they were requested to depict, ie, that of an active alcoholic on a first visit to a physician for a complaint with some relation to alcohol use (eg, accidents, abdominal pain, depression, insomnia). SPs were given liberty to provide their own details regarding their medical and social history. They were asked to admit to drinking alcohol, but be vague and evasive at first, giving more details if the doctor was persistent in asking about quantity and frequency. In response to brief intervention, they were asked to be somewhat resistant at first then agree at least to consider the student's suggestions and come back for a follow-up visit. Specifically, they were told that one purpose of the exercise was to give students the message that at least some alcoholic patients are open to talking about recovery, and that it is worth taking the time to talk with other patients in the future. For that reason, they were asked not to portray a patient in total denial, but rather an ambivalent patient in some degree of denial who begins to open up with a physician demonstrating concern and investing time in conversation about drinking. After the interviews, all students and patients participated in a debriefing session in which SPs were asked to give positive feedback on something the student did well, one suggestion on something that might improve future interviews, and spend 5 minutes each sharing their recovery stories.

The baseline survey was readministered to all students 1 month and again 9 months after the workshop during the final year of medical school training to determine if confidence in and perceived importance of the various components of alcohol SBI increased as a result of the workshop and if changes would be retained over time. Follow-up rates were $97.5 \%$ at 1 month and $63 \%$ at 9 months, with slightly better rates for the intervention group (68\%) than for the control group (55\%). To test for possible response bias, independent-samples tests were performed on baseline importance and confidence items comparing those completing the 9-month follow-up with those who did not respond. The results showed significant differences on only two of the eleven importance items and none of the confidence items.

Individual items were summed to create importance and confidence scale scores (possible range 11-110) at each of the three time periods (baseline, 1 month, and 9 months). Analyses were conducted using a mixed analysis of variance design. Significant interactions indicate a significant difference between the workshop and control groups. Free text answers were entered into an Excel file and independently grouped into areas with common themes by two of the study's authors.

\section{Results Comparison of workshop students with control group}

Paired-samples $t$-tests of individual importance and confidence items showed that 18 of 22 items, including each of the eleven confidence items, increased significantly over baseline scores. At the 9-month follow-up, 12 of 22 individual means continued to be higher when compared with baseline.

At baseline, the mean score on the importance scale was $84.6 \pm 15.7$ with a range of $39-110$, while the mean score on the confidence scale was $92.1 \pm 12.9$ with a range of $38-110$. Changes in the mean scale scores resulting from the workshop were tested using separate mixed analyses of variance. The results are shown in Table 1.

There was a significant interaction effect between confidence and group $[F(2,174)=9.13]$, indicating that the overall level of confidence in SBI differed significantly between students in the workshop group and those in the control group. The $F$-statistic for the main effect of the intervention was not statistically significant $[F(2,174)=2.13]$, suggesting that the workshop did not significantly increase students' overall confidence in performing SBI.

Contrasts were performed comparing 1-month and 9-month scores on confidence with baseline scores for the workshop and control group. These contrasts revealed a significant interaction when comparing the two groups' scores at 1 month with baseline $[F(1,87)=14.89]$. Contrasts comparing 9-month scores with baseline were not statistically significant $[F(1,87)=0.420]$, as shown in Figure 1 .

For the importance measure, there was also a significant interaction effect with group $[F(2,174)=3.34]$, indicating that 
Table I Changes in mean aggregate confidence and importance scores for workshop and control group at baseline, and I month and 9 months post intervention

\begin{tabular}{|c|c|c|c|c|c|}
\hline \multirow{2}{*}{$\begin{array}{l}\text { Aggregate } \\
\text { scores }\end{array}$} & \multicolumn{5}{|c|}{ Mean scores } \\
\hline & $\begin{array}{l}\text { Baseline } \\
\text { (SD) }\end{array}$ & $\begin{array}{l}\text { I } \\
\text { month (SD) }\end{array}$ & $\begin{array}{l}9 \\
\text { months (SD) }\end{array}$ & $\begin{array}{l}\text { F-statistic for } \\
\text { main effect }(P)\end{array}$ & $\begin{array}{l}\text { F-statistic for } \\
\text { interaction }(P)\end{array}$ \\
\hline \multicolumn{6}{|l|}{ Confidence } \\
\hline Workshop & $95.3(10.1)$ & $100.5(8.1)$ & $98.2(9.0)$ & $2.13(0.12)$ & $9.13(<0.00)$ \\
\hline Control & $92.2(12.1)$ & 88.7 (13.8) & 93.7 (13.9) & & \\
\hline \multicolumn{6}{|l|}{ Importance } \\
\hline Workshop & $84.7(16.5)$ & $94.6(14.4)$ & $95.3(10.1)$ & $14.35(<0.00)$ & $3.34(0.04)$ \\
\hline Control & 84.1 (I5.4) & $85.7(10.7)$ & $90.4(13.0)$ & & \\
\hline
\end{tabular}

Abbreviation: SD, standard deviation.

the overall level of importance of SBI differed significantly between students in the workshop group and those in the control group. In addition, the results showed a statistically significant main effect $[F(2,174)=14.35]$, suggesting a significant increase in the perceived importance of SBI among those completing the workshop. As with the confidence measure, contrasts revealed a significant interaction when comparing the two groups' scores at 1 month with baseline $[F(1,87)=5.80]$, and a nonsignificant interaction when comparing 9-month scores with baseline $[F(1,87)=1.70]$, as shown in Figure 2.

\section{Free text responses}

Results from the two open-ended questions revealed common themes for both the intervention and control groups at baseline. The two most common responses regarding factors that increased students' motivation to conduct SBI were the students' clinical experience with alcoholism and the effect of alcohol on patients' physical health. These responses occurred about three times as frequently as the next most common response, ie, the effects of alcoholism on relationships and the family. Clinical experience and physical health responses continued to be the most common response for

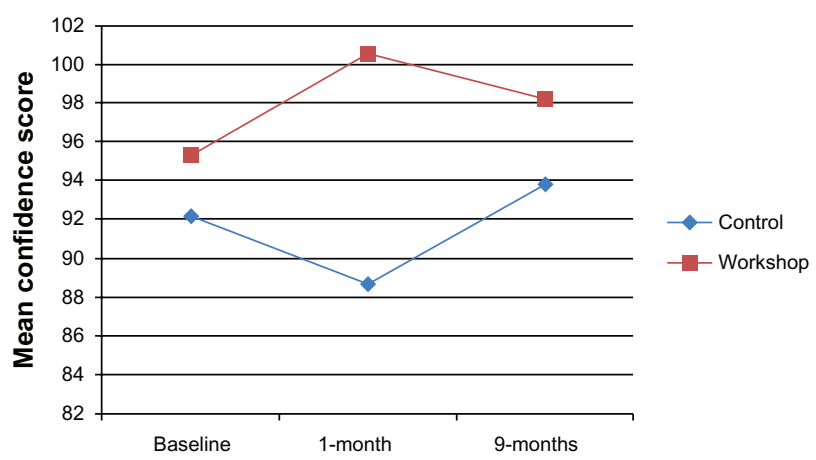

Figure I Mean confidence scores for baseline, I-month, and 9-months post intervention. both groups at the 1-month and 9-month follow-ups. At the 9-month follow-up, however, the alcohol workshop emerged as the third most common response among the intervention group, mentioned by eleven of 64 respondents.

There were less than half as many open-ended responses regarding factors that decreased motivation to screen and intervene. The most common responses for both the control and intervention groups were the difficulties associated with treating patients with alcohol disorders, the high incidence of relapse, and patients' negative reactions when asked about their alcohol use. These themes remained the most common responses for both the control and intervention groups at both the 1-month and 9-month follow-up.

\section{Discussion}

These results are consistent with previous studies in showing that brief alcohol workshops can improve medical students' confidence or self-efficacy in addressing alcohol-related problems through brief interventions. ${ }^{36,37}$ The results also indicate that these types of workshops impact student attitudes (ie, importance of performing SBI), and that changes can persist over time. Recent research has shown that implicit measures (eg, importance and confidence) are often more

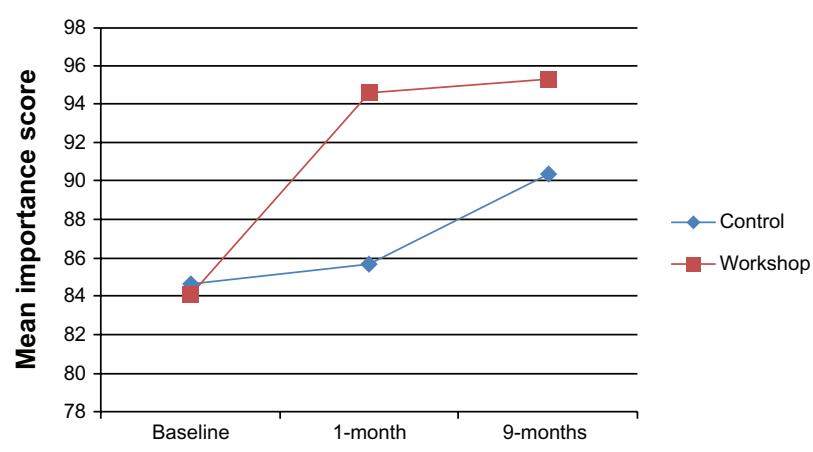

Figure 2 Mean importance scores for baseline, I-month, and 9-months post intervention. 
predictive of actual behavior than explicit measures. ${ }^{52,53}$ When compared with a control group, workshop participation was associated with higher scores on 20 of 22 importance and confidence items related to performing alcohol SBI tasks 1 month after training and 12 of 22 items after 9 months. When these items were combined into overall measures of importance and confidence, mixed analysis of variance showed statistically significant differences between the workshop group and the control group, with scores increasing for the workshop group after training but remaining static or decreasing for the control group. After 9 months, differences between the two groups converge slightly, but both confidence and importance scores remain higher for the workshop group.

The lack of a significant main effect for confidence scores is likely the result of already high mean scores on this measure (92 out of a possible 110), leaving little room for significant change. Prior to training, medical students may perceive the skills required to address patients' alcohol use as less difficult than the skills needed to address other acute or chronic conditions, resulting in inflated scores on confidence. Mean confidence scores did increase for the workshop group, but the increase was not enough to reach statistical significance.

Students' free text responses on factors that increased their motivation to screen and intervene with problem drinkers are instructive. Comments regarding factors that motivated students to intervene outnumbered comments on factors that decreased motivation by a ratio of $4: 1$. Seeing the clinical impact of problem drinking, particularly its physical sequelae, appears to be a strong motivator for students to screen and intervene. Clinical experiences with problem drinkers were the predominant motivating factor for both the intervention and control groups across all phases of the study. Mentions of the impact of alcohol on physical health were also common in both groups throughout the study. Students' free text responses regarding factors that decreased their motivation to screen and intervene with problem drinkers are also instructive, although the overall number of comments was small. Students in both the control and intervention groups most commonly listed the difficulty in treating problem drinkers and high relapse rates, factors that would appear to relate to the "treatment pessimism" described in previous studies. ${ }^{54}$ Similarly, patients' negative responses to questions about alcohol decreased students' motivation, perhaps reflecting many physicians' desires to have positive patient encounters that leave both patients and physicians feeling good after the encounter. Future studies may wish to explore whether these factors decline as students become more proficient in interview techniques, such as motivational interviewing, that focus on collaborative approaches equipping students to assist patients in evoking their own reasons and rationale for change..$^{55}$

The most innovative aspect of this study is the use of recovering alcoholics as simulated patients. Using brief predetermined scenarios, the patient-actors have the freedom to use details from their own personal experience to make the interview more realistic. Students are not told in advance that the SPs are recovering alcoholics. During the debriefing period at the end of the workshop, students often make positive comments about the authenticity of the answers and emotional reactions of SPs. This suggests that the SP approach may combine positive aspects of both "real" patient and standardized patient encounters by providing both authenticity and the opportunity for feedback. ${ }^{49}$ As SPs reveal their recovery status at the close of the workshop, students may recognize the "hidden" nature of alcohol misuse and realize the importance of screening everyone in their future practices. One potential area for future study would be to attempt to measure the impact of such an experience on students' commitment to routinely screen all patients for alcohol misuse and intervene as indicated (so-called "therapeutic commitment") and on their actual SBI practice behaviors.

The study has several limitations. Students were not randomized to the control and intervention conditions, although there is no indication that there are systematic differences between the two groups that would affect the study results. Nonetheless, there were baseline differences in the control and intervention groups that limit our ability to attribute all these changes to the workshop alone. Reasons for these differences are unclear. Surveys were administered by office personnel during the family medicine rotation orientation, making it unlikely that these responses reflect a social desirability bias.

While the use of recovering SPs is a unique addition to the workshop, it is not possible to separate the effect of this aspect of the workshop from the workshop's other components. Future studies should randomize students into workshops with and without recovering SPs to determine if there is an independent effect of this workshop component.

The follow-up rates at 9 months may also have impacted the study results, particularly the low follow-up rate (55\%) for control group participants at the 9-month follow-up. This could impact both the statistical power necessary to identify statistically significant results as well as introduce possible nonresponse bias. 
Finally, there was variability in the training of SPs, with some receiving more extensive training than others. This variability could have been reflected in the SP/student encounter. We are unable to link individual SPs to student responses and therefore unable to account for difference in training in the study results.

Overall, the study indicates a very positive impact of a brief alcohol workshop. Future studies should attempt to link the impact of such a workshop to alcohol SBI behaviors after students move into residency.

\section{Disclosure}

The authors report no conflicts of interest in this work.

\section{References}

1. Rehm J, Mathers C, Popova S, Thavorncharoensap M, Teerawattananon Y, Patra J. Global burden of disease and injury and economic cost attributable to alcohol use and alcohol-use disorders. Lancet. 2009;373: 2223-2233.

2. Moriarty HJ, Stubbe MH, Chen L, et al. Challenges to alcohol and other drug discussions in the general practice consultation. Fam Pract. 2012;29:213-222.

3. O'Connor PG, Nyquist JG, McLellan AT. Integrating addiction medicine into graduate medical education in primary care: the time has come. Ann Intern Med. 2011;154:56-59.

4. Gryczynski J, Mitchell SG, Peterson TR, Gonzales A, Moseley A, Schwartz RP. The relationship between services delivered and substance use outcomes in New Mexico's Screening, Brief Intervention, Referral and Treatment (SBIRT) Initiative. Drug Alcohol Depend. 2011;118:152-157.

5. McQueen J, Howe TE, Allan L, Mains D, Hardy V. Brief interventions for heavy alcohol users admitted to general hospital wards. Cochrane Database Syst Rev. 2011;8:CD005191.

6. Moyer A, Finney JW, Swearingen CE, Vergun P. Brief interventions for alcohol problems: a meta-analytic review of controlled investigations in treatment-seeking and nontreatment-seeking populations. Addiction. 2002;97:279-292.

7. Bertholet N, Daeppen J-B, Wietlisbach V, Fleming M, Burnand B. Reduction of alcohol consumption by brief alcohol intervention in primary care: systematic review and meta-analysis. Arch Intern Med. 2005;165:986-995.

8. Kaner EF, Dickinson HO, Beyer F, et al. The effectiveness of brief alcohol interventions in primary care settings: a systematic review. Drug Alcohol Rev. 2009;28:301-323.

9. Madras BK, Compton WM, Avula D, Stegbauer T, Stein JB, Clark HW. Screening, brief interventions, referral to treatment (SBIRT) for illicit drug and alcohol use at multiple healthcare sites: comparison at intake and 6 months later. Drug Alcohol Depend. 2009;99:280-295.

10. Wilson GB, Heather N, Kaner EF. New developments in brief interventions to treat problem drinking in nonspecialty health care settings. Curr Psychiatry Rep. 2011;13:422-429.

11. Cunningham RM, Harrison SR, McKay MP, et al. National survey of emergency department alcohol screening and intervention practices. Ann Emerg Med. 2010;55:556-562.

12. Babor TE, Higgins-Biddle J, Dauser D, Higgins P, Burleson JA. Alcohol screening and brief intervention in primary care settings: implementation models and predictors. J Stud Alcohol. 2005;66:361-368.

13. Fleming MF. Screening and brief intervention in primary care settings. Alcohol Res Health. 2004-2005;28:57-62.

14. Friedmann PD, McCullough D, Chin MH, Saitz R. Screening and intervention for alcohol problems. A national survey of primary care physicians and psychiatrists. J Gen Intern Med. 2000;15:84-91.
15. Kelleher S, Cotter P. A descriptive study on emergency department doctors' and nurses' knowledge and attitudes concerning substance use and substance users. Int Emerg Nurs. 2009;17:3-14.

16. Ozer EM, Adams SH, Lustig JL, et al. Increasing the screening and counseling of adolescents for risky health behaviors: a primary care intervention. Pediatrics. 2005;115:960-968.

17. Beich A, Gannik D, Malterud K. Screening and brief intervention for excessive alcohol use: qualitative interview study of the experiences of general practitioners. BMJ. 2002;325:870.

18. Kaner EF, Heather N, Brodie J, Lock CA, McAvoy BR. Patient and practitioner characteristics predict brief alcohol interventions in primary care. Br J Gen Pract. 2001;51:822-827.

19. National Center on Addiction and Substance Abuse. Missed Opportunity: CASA National Survey of Primary Care Physicians and Patients on Substance Abuse. New York, NY, USA: National Center on Addiction and Substance Abuse, Columbia University; 2000.

20. Spandorfer JM, Israel Y, Turner BJ. Primary care physicians' views on screening and management of alcohol abuse: inconsistencies with national guidelines. J Fam Pract. 1999;48:899-902.

21. Fleming M, Manwell LB. Brief intervention in primary care settings: a primary treatment method for at-risk, problem, and dependent drinkers. Alcohol Res Health. 1999;23:128-137.

22. Kaner EF, Lock CA, McAvoy BR, Heather N, Gilvarry E. A RCT of three training and support strategies to encourage implementation of screening and brief alcohol intervention by general practitioners. $\mathrm{Br} J$ Gen Pract. 1999;49:699-703.

23. Cape G, Hannah A, Sellman D. A longitudinal evaluation of medical student knowledge, skills and attitudes to alcohol and drugs. Addiction. 2006;10:841-849.

24. Paton A. Barriers to education about alcohol. J R Soc Med. 1992;85: 476-478.

25. World Health Organization. Report of the WHO Meeting on Undergraduate Medical Education in Substance Abuse in Europe. Geneva, Switzerland: World Health Organization; 1988.

26. AMERSA Committee on Substance Abuse Teaching Objectives. Physician Education in Substance Abuse: Curriculum Objectives. Alcohol and Drug Abuse in Medical Education. (DHHS publication number [ADM] 79-891). Washington, DC, USA: US Department of Health, Education and Welfare; 1980.

27. Council on Mental Health, American Medical Association. Medical school education on abuse of alcohol and other psychoactive drugs. JAMA. 1972;219:1746-1749.

28. Office of National Drug Control Policy. Leadership conference on medical education in substance abuse. Washington, DC, USA: Office of National Drug Control Policy; 2004. Available from: http:// webcache.googleusercontent.com/search?q=cache:http://www.ncjrs. gov/ondcppubs/publications/pdf/medical_educ_2004.pdf. Accessed January 26, 2014.

29. Kelleher S. Health care professionals' knowledge and attitudes regarding substance use and substance users. Accid Emerg Nurs. 2007; $15: 161-165$.

30. Silins E, Conigrave KM, Rakvin C, Dobbins T, Curry K. The influence of structured education and clinical experience on the attitudes of medical students towards substance misusers. Drug Alcohol Rev. 2007;26:191-200.

31. Roche AM, Parle MD, Stubbs JM, Hall W, Saunders JB. Management and treatment efficacy of drug and alcohol problems: what do doctors believe? Addiction. 1995;90:1357-1366.

32. Geller G, Levine DM, Mamon JA, Moore RD, Bone LR, Stokes EJ. Knowledge, attitudes and reported practices of medical students and house staff regarding the diagnosis and treatment of alcoholism. JAMA. 1989;261:3115-3120.

33. Indig D, Copeland J, Conigrave KM, Rotenko I. Attitudes and beliefs of emergency department staff regarding alcohol-related presentations. Int Emerg Nurs. 2009;17:23-30.

34. Jackson AH, Alford DP, Dubé CE, Saitz R. Internal medicine residency training for unhealthy alcohol and other drug use: recommendations for curriculum design. BMC Med Educ. 2010;10:22. 
35. Christison GW, Haviland MG. Requiring a one-week addiction treatment experience in a six-week psychiatry clerkship: effects on attitudes toward substance-abusing patients. Teach Learn Med. 2003;15:93-97.

36. Bell K, Cole BA. Improving medical students' success in promoting health behavior change: a curriculum evaluation. J Gen Intern Med. 2008;23:1503-1506

37. Seale JP, Shellenberger S, Tillery WK, et al. Implementing alcohol screening and intervention in a family medicine residency clinic. Subst Abus. 2005;26:23-31.

38. Chossis I, Lane C, Gache P, et al. Effect of training on primary care residents' performance in brief alcohol intervention: a randomized controlled trial. J Gen Intern Med. 2007;22:1144-1149.

39. Babor TF, Higgins-Biddle JC, Higgins PS, Gassman RA, Gould BE. Training medical providers to conduct brief alcohol screening and brief interventions. Subst Abus. 2004;25:17-26.

40. Adams A, Ockene J, Wheller E, Hurley T. Alcohol counseling: physicians will do it. J Gen Intern Med. 1998;13:692-698.

41. Richmond RL, G-Novak K, Kehoe L, Calfas G, Mendelsohn CP, Wodak A. Effect of training on general practitioners' use of a brief intervention for excessive drinkers. Aust NZJ Public Health. 1998;22: 206-209.

42. Roche AM, Stubbs JM, Sanson-Fisher RW, Saunders J. A controlled trial of educational strategies to teach medical students brief intervention skills for alcohol problems. Prev Med. 1997;26:78-85.

43. El-Guebaly N, Toews J, Lockyer J, Armstrong S, Hodgins D. Medical education in substance-related disorders: components and outcome. Addiction. 2000;95:949-957.

44. Gopalan R, Santora P, Stokes EJ, Moore RD, Levine DM. Evaluation of a model curriculum on substance abuse at The Johns Hopkins University School of Medicine. Acad Med. 1992;67:260-266.

45. Ungerleider JT, Pechnick RN, Wallbom AS, Siegel N, Fairbanks L, Ziedonis DM. Interactive teaching, medical students, and substance abuse: University and community come together in a new endeavor Acad Psychiatry. 1992;16:160-169.
46. Walsh RA, Roche AM, Sanson-Fisher RW, Saunders JB. Interactional skills of students from traditional and non-traditional medical schools before and after alcohol education. Med Educ. 2001;35:211-216.

47. Kahan M, Wilson L, Midmer D, Borsoi D, Martin D. Randomized controlled trial on the effects of a skills-based workshop on medical students' management of problem drinking and alcohol dependence. Subst Abus. 2003;24:5-16.

48. Lee JD, Triola M, Gillespie C, et al. Working with patients with alcohol problems: a controlled trial of the impact of a rich media web module on medical student performance. J Gen Intern Med. 2008;23:1006-1009.

49. Bokken L, Rethans JJ, Jöbsis Q, Duvivier R, Scherpbier A, Van der Vleuten C. Instructiveness of real patients and simulated patients in undergraduate medical education: a randomized experiment. Acad Med. 2010;85:148-154.

50. Eagles JM, Calder SA, Nicoll KS, Walker LG. A comparison of real patients, simulated patients and videotaped interview in teaching medical students about alcohol misuse. Med Teach. 2001;23:490-493.

51. US Preventive Services Task Force. Screening and Behavioral Counseling Interventions in Primary Care To Reduce Alcohol Misuse: Recommendation Statement. Ann Intern Med. 2004;140:554-556.

52. Back MD, Schmukle SC, Egloff B. Predicting actual behavior from the explicit and implicit self-concept of personality. J Pers Soc Psychol. 2009;97:533-548

53. Keatley D, Clarke DD, Hagger MS. The predictive validity of implicit measures of self-determined motivation across health-related behaviours. Br J Health Psychol. 2013;8:2-17.

54. Anderson P, Clement S. The AAPPQ revisited: the measurement of general practitioners' attitudes to alcohol problems. $\mathrm{Br}$ J Addict. 1987;82:753-759.

55. Rollnick S, Miller WR, Butler CC. Motivational Interviewing in Healthcare: Helping Patients Change Behavior. London, UK: Guilford Publications, 2008.
Advances in Medical Education and Practice

\section{Publish your work in this journal}

Advances in Medical Education and Practice is an international, peerreviewed, open access journal that aims to present and publish research on Medical Education covering medical, dental, nursing and allied health care professional education. The journal covers undergraduate education, postgraduate training and continuing medical education

\section{Dovepress}

including emerging trends and innovative models linking education, research, and health care services. The manuscript management system is completely online and includes a very quick and fair peer-review system. Visit http://www.dovepress.com/testimonials.php to read real quotes from published authors. 